\title{
Controlled Release of Ursodeoxycholic Acid from Pullulan Acetate Nanoparticles to Modulate Glutamate-Induced Excitotoxicity in PC-12 Cells
}

\author{
Kwang Sik Yu, ${ }^{1}$ Jun Young Oh, ${ }^{2}$ Min Cheol Kim, ${ }^{3}$ Seong Hee Kang $\mathbb{D}^{4},{ }^{4}$ Nam Seob Lee, \\ Seung-Yun Han, ${ }^{1}$ Ki Hyun Ryu $\mathbb{D}^{5,},{ }^{5,6}$ Young Gil Jeong $\mathbb{D}^{1},{ }^{1}$ and Do Kyung Kim $\mathbb{D}^{1}$ \\ ${ }^{1}$ Department of Anatomy, College of Medicine, Konyang University, Daejeon 302-718, Republic of Korea \\ ${ }^{2}$ Department of Neuroscience and Physiology, Dental Research Institute, BK21-Plus, School of Dentistry, \\ Seoul National University, Seoul 08826, Republic of Korea \\ ${ }^{3}$ Department of Mechanical Engineering, Massachusetts Institute of Technology, Cambridge, MA 02139, USA \\ ${ }^{4}$ Department of Radiological Science, Konyang University, Daejeon 302-718, Republic of Korea \\ ${ }^{5}$ Department of Internal Medicine, College of Medicine, Konyang University, Daejeon 302-718, Republic of Korea \\ ${ }^{6}$ Myunggok Research Institute, College of Medicine, Konyang University, Daejeon 302-718, Republic of Korea
}

Correspondence should be addressed to Ki Hyun Ryu; medidrug@kyuh.ac.kr, Young Gil Jeong; ygjeong@konyang.ac.kr, and Do Kyung Kim; dokyung@konyang.ac.kr

Received 15 October 2017; Revised 4 January 2018; Accepted 17 January 2018; Published 4 March 2018

Academic Editor: Jin-Ho Choy

Copyright (C) 2018 Kwang Sik Yu et al. This is an open access article distributed under the Creative Commons Attribution License, which permits unrestricted use, distribution, and reproduction in any medium, provided the original work is properly cited.

\begin{abstract}
The neuroprotective effects of the ursodeoxycholic acid- (UDCA-) loaded pullulan acetate (PA) (UDCA-PA) nanospheres stabilized by poly(vinyl alcohol) (PVA) were identified by in vitro study. The UDCA-PA nanospheres were constructed by nanoemulsion process. The UDCA-PA nanospheres were analyzed using Fourier transform-infrared spectroscopy (FT-IR) and transmission electron microscopy (TEM). Then, the UDCA-PA nanospheres were used to treat PC-12 neuronal cells, which were formerly triggered by glutamate-induced excitotoxicity. As a result, the cells treated with the UDCA-PA nanospheres showed higher survival rate against glutamate-induced excitotoxicity. Furthermore, the UDCA-PA nanospheres decreased immunoreactivity of Annexin V, a membrane marker for apoptotic cells, in PC-12 with glutamate-induced injury. Particularly, the UDCA-PA nanospheres decreased the level of apoptosis-related proteins such as caspase-3. Taken together, the UDCA-PA nanospheres increased neuroprotective effects against glutamate-induced neuronal damage via inhibition of apoptosis at low concentration.
\end{abstract}

\section{Introduction}

Primary biliary cirrhosis $(\mathrm{PBC})$ and the related disorders are raised by obstruction caused with a variety of damage to the bile ducts in the liver [1]. Much like other forms of liver disease, PBC permanently damages the liver and eventually can lead to liver failure because of irreversible replacement of normal liver parenchyma by fibrotic scar tissue [2]. Liver failure can induce generalized hyperammonemia that is thought to be the underlying cause of hepatic encephalopathy $(\mathrm{HE})[3,4]$. The precise pathological mechanisms underlying hyperammonemia-mediated $\mathrm{HE}$ are not clear, and the deregulation of multiple neurotransmitter systems has been reported as the key [5].
Among the diverse neurotransmitter systems in human, the glutamatergic neurotransmitter system is seemingly the most affected in HE [6]. Numerous experimental models of acute liver failure established a direct link between HE and increased brain glutamate load [7-9]. Mechanistically, acute injections of ammonia into the brain triggered rapid neuronal death mediated through the excitotoxicity characterized by overactivation of N-methyl-D-aspartate (NMDA) receptor, a subset of ionotropic glutamate receptor [10]. The downstream targets of NMDA receptor overactivation are complex and appear to involve the interplay of a number of factors, including oxidative stress, activation of certain cell-cycle genes, and apoptosis [11-13]. In fact, expressions of antiapoptotic proteins such as $\mathrm{Bcl}-2$ and $\mathrm{Bcl}-\mathrm{xL}$ are downregulated, 
whereas proapoptotic Bax expression is enhanced in neurons of experimental model of HE [14]. Caspase-3, an important apoptotic executioner in many cell types, is also activated in neurons in animal model of HE [15]. Thus, pharmaceutical inhibition of glutamate-mediated excitotoxicity might confer the preventive means for development of PBC-associated HE by reducing the neuronal apoptosis.

The UDCA is the currently accepted oral pharmaceutic for treating PBC [16]. Combined analysis of the three largest randomized clinical trials of UDCA for PBC indicated that UDCA improved clinical and biochemical indices and prolonged survival free of liver transplantation [17]. Although the cytoprotective mechanisms by which UDCA acts remain unclear, experimental evidence suggests three primary mechanisms of action: protection against the cytotoxicity of hydrophobic bile acids, stimulation of hepatobiliary secretion, and protection of hepatocytes against bile acid-induced apoptosis [18-20]. However, to the best our knowledge, reports to elucidate whether usage of UDCA could be beneficial on HE prevention in in vivo setting through direct modulation of excitotoxic neuronal death are currently absent. At least partly, the lack of study on therapeutic effect of UDCA on HE in vivo is thought to be due to the limited solubility and/or bioavailability of UDCA. In fact, many bile acid formulations including UDCA exist as a solid form of bile acid either as a component of a tablet or as a particle and/or precipitate in a solution or suspension [21]. Complete solubilization of UDCA crystals might be possible at an endoluminal $\mathrm{pH}$ in small intestine over about 8.4 , but this value has been unobtainable ex vivo [22]. Accordingly, many existing forms of UDCA have not been appropriate for systemic administration [23]. This, in turn, means that the levels of bile in systemic circulation following administration of many existing forms of UDCA may be extremely low. Therefore, many UDCA formulations have limited utility for delivering UDCA systemically and even less utility for delivering UDCA to the brain [24].

Treatment with a target oriented Drug Delivery System (DDS), which enables the insoluble drugs to be soluble and thus enables direct intravenous administration of a drug to a patient, is recognized as a promising technology because its side effects are remarkably diminished while preserving original therapeutic effects. Polymer nanoparticles stabilized by surfactants provide specific benefits with regard to the stable and controllable release of various drugs that are loaded when administered intravenously. DDS study has evolved polymers that can effectively transport the drug to a target place and their therapeutic benefits while minimizing their side effects $[25,26]$.

In this study, we manufactured the novel functionalized nanospheres, namely, the UDCA-PA, by encapsulating hydrophobic UDCA with amphiphilic pullulan acetate nanosphere to enhance the dispersability in aqueous media. As described above, as glutamate-induced excitotoxicity is known to be the key mechanism underlying the HE-mediated neuronal death, we examined the in vitro neuroprotective effects and the possible antiapoptotic mechanisms of the UDCA-PA using PC-12 cells, rat pheochromocytoma cells, formerly challenged with glutamate-induced excitotoxicity.

\section{Experimental}

2.1. Chemical and Reagents. Ursodeoxycholic acid $\left(\mathrm{C}_{24} \mathrm{H}_{40}\right.$ $\mathrm{O}_{4}$ ) was friendly provided by Daewoong Pharmaceutical Co., Ltd.; pullulan and pyrene were supplied by Tokyo Chemical Co., Ltd. (Tokyo, Japan). Formamide (98.5\%), ethylenediamine (EDA), and L-glutamic acid were supplied by Junsei Chemical Co., Ltd. (Tokyo, Japan). Pyridine (99.5\%) was purchased from Kanto Chemical Co., Inc. (Tokyo, Japan). Acetic anhydride (99\%) and ethanol (EtOH, 99.9\%) were purchased from Samchun. (Kyunggido, South Korea). Dichloromethane (DCM, 99.5\%) was purchased from Biosesang (Seoul, South Korea). Poly(vinyl alcohol) (PVA, Mw of $15 \mathrm{kDa}$ ), uranyl acetate dehydrate (98\%), dimethyl sulfoxide (DMSO, 99.5\%), 1-ethyl-3-(3-dimethylaminopropyl)carbodiimide (EDC), N-hydroxysuccinimide (NHS), fluorescein isothiocyanate (FITC), and 3-[4,5-dimethylthiazol-2-yl]-2,5diphenyltetrazoli-um bromide (MTT) were supplied by Sigma-Aldrich (St. Louis, USA). All the chemicals were used without further purification. Triple distilled and deionized (DI) water is used throughout.

2.2. Cell Culture and Treatment. PC-12 cells were purchased from the Korean Cell Line Bank and maintained in DMEM medium supplemented with $10 \%$ fetal bovine serum (FBS) $(\mathrm{v} / \mathrm{v}), 1 \%$ penicillin/streptomycin $(\mathrm{P} / \mathrm{S})$, and $1 \%$ HEPES in $5 \%$ $\mathrm{CO}_{2}$ at $37^{\circ} \mathrm{C}$. PC-12 cells were cotreated with $6 \mathrm{mM}$ glutamate and different concentrations of the UDCA-PA nanospheres for $24 \mathrm{~h}$. In these experiments, glutamate was dissolved in $10 \mu \mathrm{L}$ of hydrochloride $(\mathrm{HCl})$ and $990 \mu \mathrm{L}$ of DMEM. Control group was prepared by treatment of the same amount of DMEM.

2.3. Preparation of Pullulan Acetate. PA was prepared by earlier reported Motozato et al.s method [27] with minor modifications. $2 \mathrm{~g}$ of pullulan was fully dissolved in $20 \mathrm{~mL}$ of formamide with a magnetic stirring for $4 \mathrm{~h} .6 \mathrm{~mL}$ pyridine and $15 \mathrm{~mL}$ of acetic anhydride were added to the solution and suddenly formed white colored film-like precipitation. The agglomeration in mixture solution was fully dissolved with a magnetic stirring for $12 \mathrm{~h}$. The color of the solution changed from transparent to gold. The solution was loaded in water bath with a magnetic string, with the temperature increased to $54^{\circ} \mathrm{C}$, and kept for $48 \mathrm{~h}$. A dark-brown mixture was obtained, which was further purified by triturating with $1,000 \mathrm{~mL}$ distilled water and $500 \mathrm{~mL}$ methanol. The solid material was dried in vacuum for $24 \mathrm{~h}$. The sample was sealed in $50 \mathrm{~mL}$ vial stored at $-20^{\circ} \mathrm{C}$ until further use [27].

2.4. Fourier Transform-Infrared Spectroscopy (FT-IR) Analysis. Fourier transform-infrared (FT-IR) spectra of pullulan, PA, UDCA, and UDCA-loaded PA nanoparticles were recorded at $20^{\circ} \mathrm{C}$ using an ALPHA FT-IR Spectrometer equipped with Platinum ATR (Bruker, USA). The samples were vacuum-dried before FT-IR scan. Spectra were measured with a resolution of in the range of $1 \mathrm{~cm}^{-1}$ and the wavenumber range was $4,000 \sim 400 \mathrm{~cm}^{-1}$. The samples were measured by dropping the samples on the surface of facet of 
diamond ATR without any specific preparation of specimens. Total of 24 scans were taken for each sample.

\subsection{Critical Aggregation Concentration (CAC) of PA Nanopar-} ticles in Aqueous Medium. The critical aggregation concentration (CAC) of PA nanoparticles was calculated by the fluorescence probe technique. Briefly, $36 \mathrm{uL}$ pyrene solutions $\left(5.0 \times 10^{-5} \mathrm{M}\right)$ in acetone were added to a series of $15 \mathrm{~mL}$ tubes and followed by drying with $\mathrm{N}_{2}$ to evaporate the acetone. Afterward, a series of PA nanoparticles in the range $1.0-10^{-3} \mathrm{~g} / \mathrm{L}$ were added to each tube. The final concentration of pyrene in each sample was $6.0 \times 10^{-7} \mathrm{M}$. The tube was sonicated in an ultrasonic bath for $15 \mathrm{~min}$ for equilibrium and left overnight at room temperature. The emission spectra of the samples were performed at the range $300-360 \mathrm{~nm}$ using fluorospectrophotometer (RF-5301PC, Shimadzu Japan) at the excitation wavelength of $335 \mathrm{~nm}$.

2.6. Preparation of UDCA-PA Nanospheres. The UDCAPA nanospheres were synthesized by oil-in-water $(\mathrm{o} / \mathrm{w})$ emulsion-solvent evaporation method with minor modifications [28]. $10 \mathrm{mg}$ UDCA and $100 \mathrm{mg}$ PA were dissolved in $5 \mathrm{~mL}$ DCM into $20 \mathrm{~mL}$ vial with sonication; this constituted mixture. For primary emulsion, the mixture was dropped into $10 \mathrm{~mL}$ aqueous PVA $(0.5 \%, \mathrm{w} / \mathrm{w})$ solution with magnetic stirring $(700 \mathrm{rpm})$. The mixture was using a probe sonicator for $30 \mathrm{~s}$. The resulting colloidal suspension was centrifuged at $20,000 \times \mathrm{g}$ for $30 \mathrm{~min}$ to obtain the UDCA-PA nanospheres. To remove the impurities and free UDCA, the sample was redispersed in DI water and precipitated 3 times at 20,000 $\times \mathrm{g}$ for $15 \mathrm{~min}$ each. Washed solid material was resuspend in DI water, subjected to prefreezing at $-40^{\circ} \mathrm{C}$ for $12 \mathrm{~h}$, and, furthermore, vacuum-dried at $-110^{\circ} \mathrm{C}$ for $24 \mathrm{~h}$ by Speedvac [29]. The lyophilized powder was sealed in sealed $50 \mathrm{~mL}$ vial stored at $-20^{\circ} \mathrm{C}$ until further use.

2.7. Calculation of Entrapment Efficiency (E\%). To increase the detection efficacy, FITC was attached to UDCA. First, $5 \mathrm{mg}$ of UDCA was dissolved in $1 \mathrm{~mL}$ of ethanol; $1 \mathrm{mg}$ of EDC and $1 \mathrm{mg}$ of NHS were added and then reacted for $15 \mathrm{~min}$. The sample was then precipitated by centrifugation and the upper part was decanted. The precipitate was washed twice with ethanol and redispersed in $1 \mathrm{~mL}$ of ethanol. Then, $50 \mu \mathrm{L}$ of ethylenediamine was added and reacted for $1 \mathrm{~h}$. The sample was precipitated using centrifugation and the supernatant was decanted. The precipitate was washed twice with ethanol again and redispersed in $1 \mathrm{~mL}$ of ethanol. UDCA-FITC sample was finally prepared by adding $1 \mathrm{mg}$ FITC to amine activated UDCA and then reacting for an additional $24 \mathrm{~h}$. The sample was dried for $24 \mathrm{~h}$ by Speedvac. Entrapment efficiency of the FITC-UDCA in nanoparticles was calculated as follows: After separation of nanoparticles from the aqueous buffer, the extract including the repeated washing was collected. To a $100 \mathrm{~mL}$ of this solution, $500 \mathrm{~mL}$ of phosphate buffer saline (PBS), $\mathrm{pH}-7.4$, was added and the concentration of the FITC-UDCA was measured spectrophotometrically at $495 \mathrm{~nm}$. The emission spectra of the samples were performed at $519 \mathrm{~nm}$ using fluorospectrophotometer (RF-5301PC, Shimadzu, Japan) at the excitation wavelength of $495 \mathrm{~nm}$. Amount of FITC-UDCA present was calculated from the standard curve of the drug. Total amount of FITCUDCA left in the aqueous extract was subtracted from the amount of FITC-UDCA originally added in the reaction medium, and the entrapment efficiency $(E \%)$ was calculated from the ratio of the amount of FITC-UDCA entrapped to the total amount of FITC-UDCA added $\times 100$.

2.8. Release Profile of FITC-UDCA from Nanoparticles. A known amount of lyophilized powder of pullulan nanoparticles loaded with FITC-UDCA was dispersed in $10 \mathrm{~mL}$ of PBS, $\mathrm{pH}=7.4 .200 \mathrm{ml}$ of the solution was distributed in eppendorf tubes and kept at $37^{\circ} \mathrm{C}$. At a predetermined interval of time, the solution was filtered through a Millipore filter $(100 \mathrm{kD}$ cut off). Free FITC-UDCA present in aqueous buffer passed through the filter and its concentration was determined spectrophotometrically at $\max =495 \mathrm{~nm}$.

2.9. Transmission Electron Microscopy (TEM) Analysis. The particle size, morphology, and distribution quality of UDCAPA nanospheres were analyzed by Hitachi H-7650 TEM (EVISA, Japan) following negative staining with uranyl acetate solution. TEM imaging was prepared from the UDCA-PA nanospheres resuspend in distilled water with sonication for $1 \mathrm{~min}$. After sonication, $10 \mu \mathrm{g}$ of the UDCA-PA nanospheres was mixed with $100 \mu \mathrm{L}$ uranyl acetate solution and then dropped on TEM-copper grids. Representative samples of TEM images for the estimation of size and morphology of the UDCA-PA nanospheres.

2.10. MTT Assays. The cell viability was measured by MTT assay. In brief, PC-12 cells were seeded in 96-well culture plates at cell density of $5 \times 10^{4}$ per well and maintained in $5 \%$ $\mathrm{CO}_{2}$ incubator at $37^{\circ} \mathrm{C}$ for $24 \mathrm{~h}$. PC- 12 cells were treated with various concentrations of UDCA-PA nanospheres $(1,5,10$, 25 , and $50 \mu \mathrm{g} / \mathrm{mL}$ ) with or without glutamate for $24 \mathrm{~h}$. After adding the UDCA-PA nanospheres, the plates were further incubated for another $24 \mathrm{~h} .10 \mu \mathrm{L}$ of MTT solution $(5 \mathrm{mg} / \mathrm{ml})$ was added to each well in 96-well plate and incubated at $37^{\circ} \mathrm{C}$ for $4 \mathrm{~h}$. The medium was carefully removed and cells which had formazan were dissolved with $100 \mu \mathrm{L}$ of DMSO. The absorbance was measured at $540 \mathrm{~nm}$ using an ELx800uv microplate reader (BioTek Instruments, Inc., USA).

2.11. Annexin $V$ Binding Assay. The cellular apoptosis was determined using an Annexin V \& Dead Cell kit (Merck Millipore, Germany) according to the manufacturer's instructions. Briefly, PC-12 cells were seeded in 12-well culture plates at cell density of $5 \times 10^{5}$ per well and maintained in $5 \%$ $\mathrm{CO}_{2}$ incubator at $37^{\circ} \mathrm{C}$ for $24 \mathrm{~h}$. PC-12 cells were treated with various concentrations of UDCA-PA nanospheres $(1,5,10$, 25 , and $50 \mu \mathrm{g} / \mathrm{mL}$ ) with or without glutamate for $24 \mathrm{~h}$. After adding the UDCA-PA nanospheres, the plates were further incubated for another $24 \mathrm{~h}$ and then washed twice with cold PBS. Trypsin was used to dissociate the PC-12 cells from the 12-well plates, then $100 \mu \mathrm{L}$ fresh medium was added to each tube. $100 \mu \mathrm{L}$ of the Muse ${ }^{\mathrm{TM}}$ Annexin V \& Dead Cell reagent was added to each tube mix thoroughly by vortexing at a medium speed for 3 to $5 \mathrm{sec}$. Samples were incubated at room 


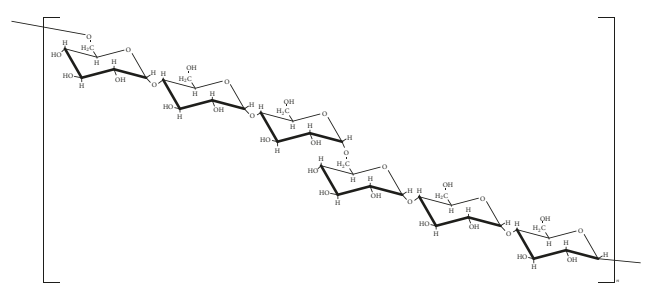

(a) Pullulan

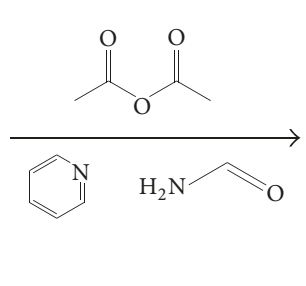



(b) Pullulan acetate
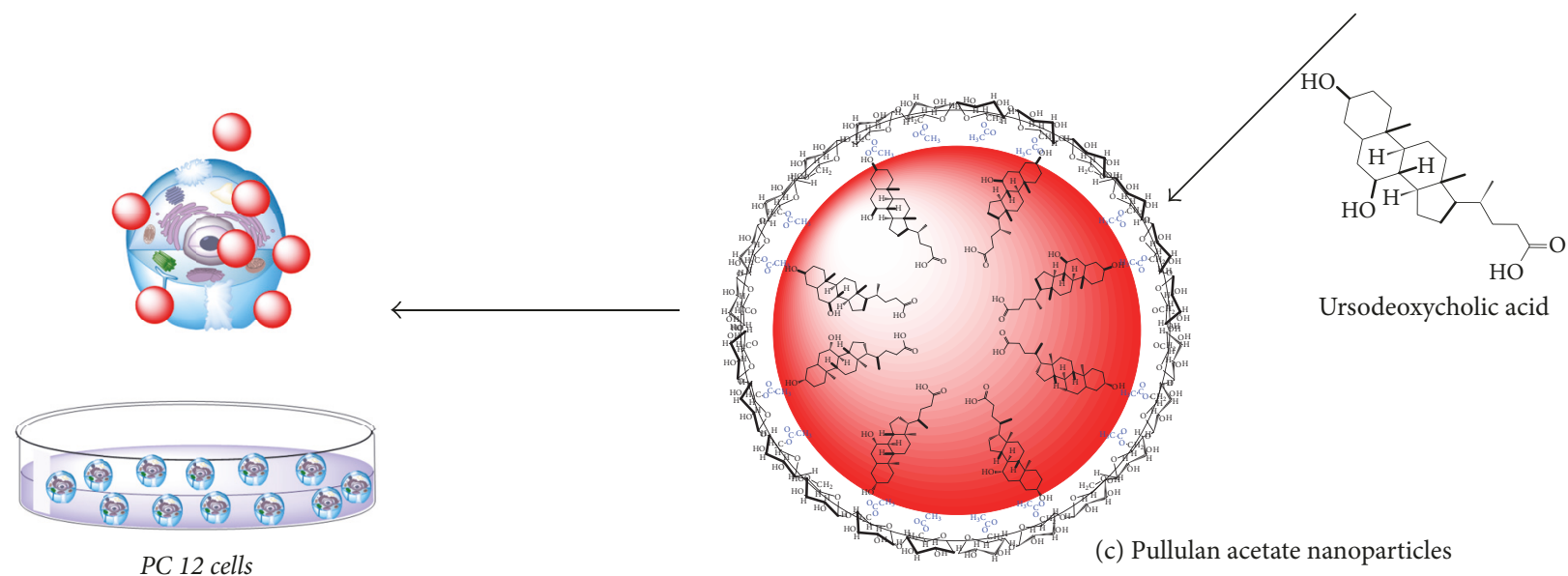

SCHEme 1: Schematic representation of the synthesis of ursodeoxycholic acid-loaded pullulan acetate nanoparticles. (a) Chemical structure of pullulan; (b) synthesis of pullulan acetate in the presence of acetic anhydride, pyridine, and formamide; and (c) incorporation of ursodeoxycholic acid into pullulan acetate nanoparticles by microemulsion method.

temperature for $20 \mathrm{~min}$. The samples were determined by the Muse Cell Analyzer. Samples were analyzed with the aid of a Muse cell analyzer (Merck Millipore, Germany). Using Muse Cell Analyzer, live, early apoptotic, late apoptotic, debris, and total apoptotic cells of each group at indicated concentrations of the UDCA-PA nanospheres were evaluated.

2.12. Immunofluorescence Assay. The expression of apoptosis-related protein such as caspase-3 was determined using an immunofluorescence assay. Coverslips in 12-well plates were coated by poly-L-lysine. Briefly, PC-12 cells were seeded in 12-well culture plates at cell density of $1 \times 10^{6}$ per well and maintained in $5 \% \mathrm{CO}_{2}$ incubator at $37^{\circ} \mathrm{C}$ for $12 \mathrm{~h}$. PC-12 cells were treated with various concentrations of UDCA-PA nanospheres $(1,5,10,25$ and $50 \mu \mathrm{g} / \mathrm{mL})$ with or without glutamate for $24 \mathrm{~h}$. After adding the UDCA-PA nanospheres, the plates were further incubated for another $24 \mathrm{~h}$ and then washed twice with cold PBS. After being fixed in $4 \%$ paraformaldehyde at $4^{\circ} \mathrm{C}$ for $1 \mathrm{~h}$, cells were then permeabilized with $1 \%$ Triton X-100 for $1 \mathrm{~h}$ and blocked with $5 \% \mathrm{BSA}$ at $4^{\circ} \mathrm{C}$ for $1 \mathrm{~h}$. Cells were incubated with primary antibody (anti-rabbit caspase-3; Sigma-Aldrich, MO, USA) in blocking solution at room temperature (RT) for $1 \mathrm{~h}$, stained with secondary antibody (FITC-conjugated anti-rabbit IgG) for $1 \mathrm{~h}$ (light protected), and then washed twice with cold PBS. Finally, the coverslips were rinsed with distilled water and mounted with the cells facing down on the glass slides. Cells were observed using LSM 510 confocal laser scan microscope (Zeiss, Inc., USA) and E800 epifluorescence microscopic (Nikon, Inc., Japan).
2.13. Western Blot. Briefly, PC-12 cells were seeded in 100 $\varnothing$ cell culture dish at cell density of $5 \times 10^{6}$ per well and maintained in $5 \% \mathrm{CO}_{2}$ incubator at $37^{\circ} \mathrm{C}$ for $24 \mathrm{~h}$. PC-12 cells were cotreated at the UDCA-PA nanospheres (1 and $5 \mu \mathrm{g} / \mathrm{mL}$ ) with or without glutamate $2 \sim 10 \mathrm{mM}$ for $24 \mathrm{~h}$. After adding the UDCA-PA nanospheres, the plates were further incubated for another $24 \mathrm{~h}$ and then washed twice with cold PBS. Protein was collected by lysing the cells in $100 \mu \mathrm{L}$ of ice cold PRO-PREPTM buffer (iNtRON, Seongnam, Korea). The protein concentration of supernatant was evaluated with BCA protein assay kit (Thermo Scientific, South Logan, UT, USA). Total proteins $(10 \mu \mathrm{g})$ were separated by $15 \%$ SDS-PAGE and blotted onto a transferred polyvinylidene fluoride (PVDF) membrane. The membranes were blocked with $5 \%$ skin milk at RT for $4 \mathrm{~h}$ and then incubated with rabbit primary antibodies to cleaved caspase-3 (1:1,000 each) and at $4^{\circ} \mathrm{C}$ for $12 \mathrm{~h}$. The membranes were washed with Trisbuffered saline containing $0.1 \%$ Tween 20 (T/TBS) for $10 \mathrm{~min}$ three times and then incubated with HRP-conjugated antirabbit IgG secondary antibodies (1:1,000 each) at RT for $2 \mathrm{~h}$. After three-time wash in T/TBS, bands were developed using chemiluminescence detection kit (Thermo Scientific, South Logan, UT, USA).

\section{Results and Discussion}

3.1. Synthesis and Characterization of PA. As shown in Scheme 1, pullulan was first replacing the hydroxyl groups in the glucose unit with acetate groups with acetic anhydride, pyridine, and formamide in order to prepare PA as 


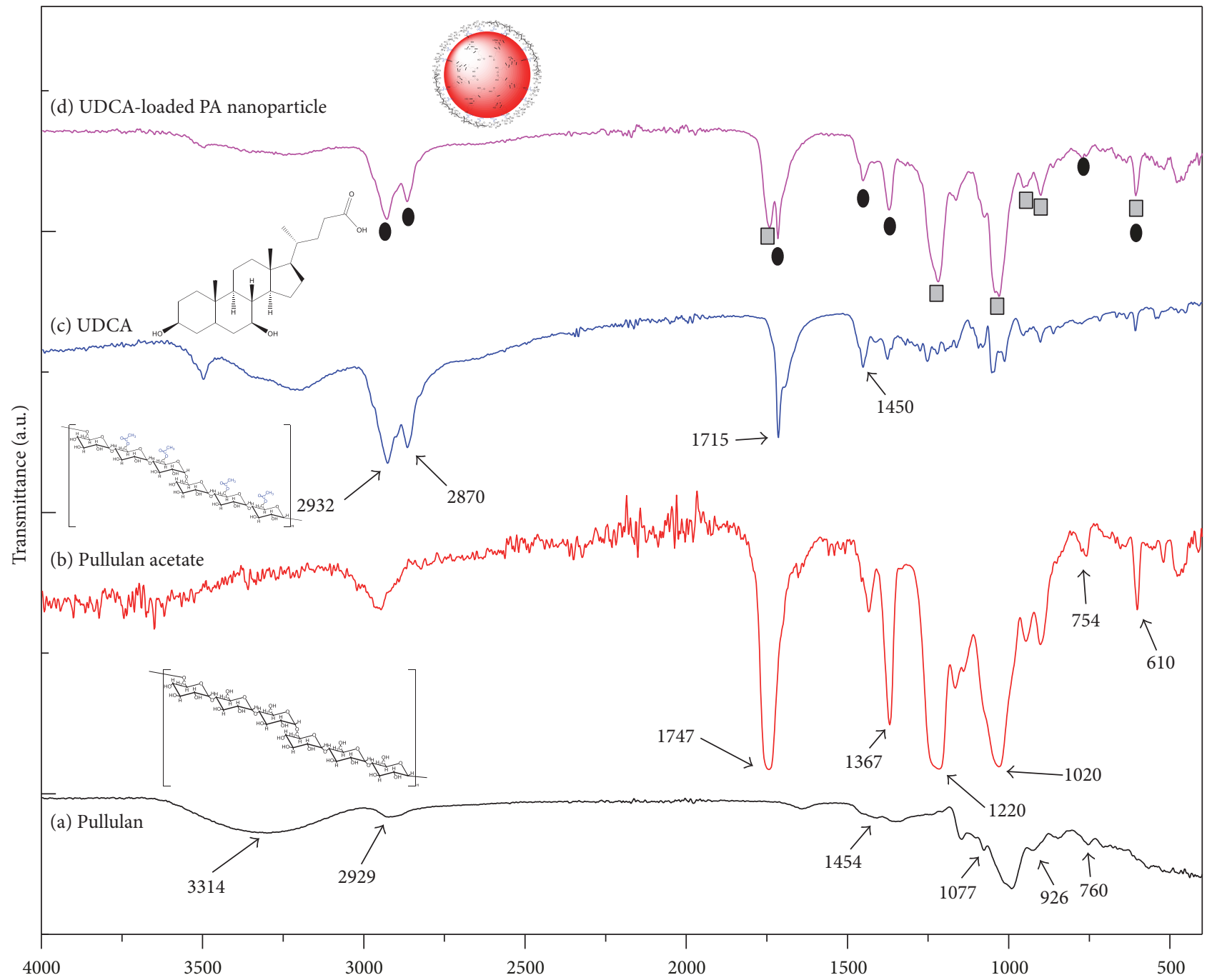

FIGURE 1: FT-IR spectra of (a) pullulan, (b) pullulan acetate (PA), (c) ursodeoxycholic acid (UDCA), and (d) UDCA-loaded PA nanoparticles.

an amphiphilic polymer. The degree of substitution with acetate can be tuned by changing the ratio between acetic anhydride and glucose unit. Figure 1 shows FT-IR spectra of (a) pullulan, (b) PA, (c) UDCA, and (d) UDCA-loaded PA nanoparticles. FT-IR spectra of pure pullulan show the following characteristic bands: $1077 \mathrm{~cm}^{-1}$ (C-OH stretching), $1454 \mathrm{~cm}^{-1}$ (CH stretching), and $2929 \mathrm{~cm}^{-1}$ (C-H stretching). The weak bands observed near $926 \mathrm{~cm}^{-1}$ and $760 \mathrm{~cm}^{-1}$ are $\alpha$ anomers of pyranose compounds. The broad absorption peak at $3600-3000 \mathrm{~cm}^{-1}$ can be assigned to $\mathrm{OH}$ stretching and intrahydrogen bonds. From IR spectra of pullulan acetate, the stretching vibration of hydroxyl group at ca. $3300 \mathrm{~cm}^{-1}$ converted weak, and the peak at $1747 \mathrm{~cm}^{-1}$ characteristic indicative of carbonyl group of an ester group increased because the degree of substitution (DS) of the acetyl group increased $\mathrm{CH}_{3}$ deformation at $1367 \mathrm{~cm}^{-1}$, C-O stretching at $1250 \mathrm{~cm}^{-1}$, presence of $\mathrm{O}-\mathrm{C}=\mathrm{O}$ bonds at $1020 \mathrm{~cm}^{-1}, \mathrm{CH}_{2}$ deformation at $752 \mathrm{~cm}^{-1}$, and $\mathrm{C}-\mathrm{O}$ stretching at $610 \mathrm{~cm}^{-1}$. Acetylated glycosides have a band because the acetyl $\mathrm{C}=\mathrm{O}$ stretching vibration appeared at $1747 \mathrm{~cm}^{-1}$, which is not observed for the nonacetylated compounds. In addition, the nonacetylated glycosides exhibit a band at $3600-3000 \mathrm{~cm}^{-1}$ due to the $\mathrm{OH}$ stretching vibration which is not observed in the acetylated form. By comparing the FT-IR spectrum of pullulan and pullulan acetate, the successful synthesis of the pullulan acetate was verified. The UDCA obviously has broad absorption peaks at $3300-3500 \mathrm{~cm}^{-1}$ and sharp peaks at $2800-3000 \mathrm{~cm}^{-1}$ and $1715 \mathrm{~cm}^{-1}$, which can be allocated to $(\mathrm{O}-\mathrm{H})$ stretching vibrations, $(\mathrm{C}-\mathrm{H})$ and $(\mathrm{C}=\mathrm{O})$ ones. The peak at $1450 \mathrm{~cm}^{-1}$ is due to the mixture of $\mathrm{C}-\mathrm{O}$ stretching and $\mathrm{O}-\mathrm{H}$ deformation vibration of carboxylic acid. The CAC performance of PA nanoparticles in an aqueous phase was calculated by evaluating the excitation spectra of fixed concentration of pyrene with various concentrations of PA nanoparticles as shown in Figure 2(a). The characteristic peak of excitation spectra of pyrene shifts from 334 to $337 \mathrm{~nm}$ due to the incorporation of pyrene in aqueous phase to the less polar inner core. Figure 2(b) shows the intensity ratios $\left(I_{337} / I_{334}\right)$ versus logarithm of the concentration of PA nanoparticles. The CAC value can be calculated from the 


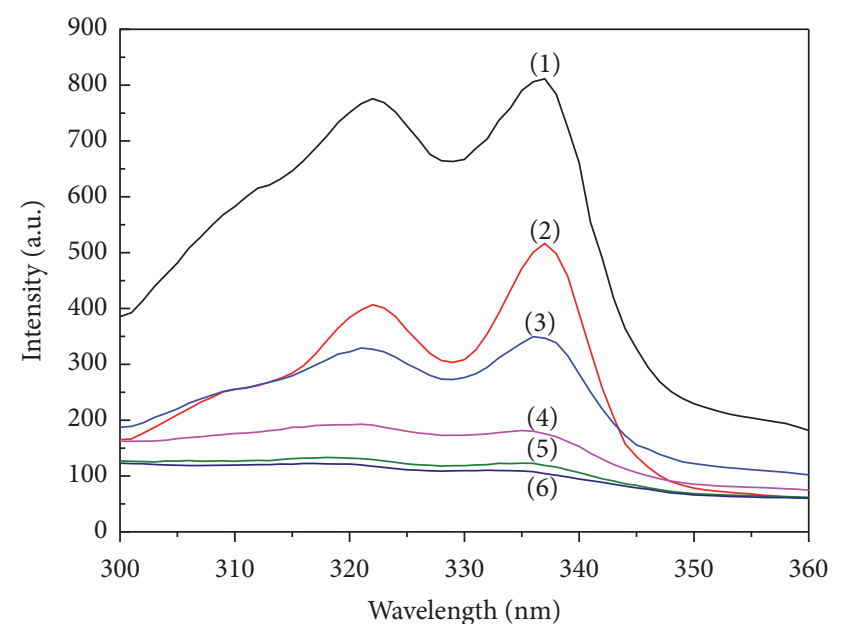
(1) $2 \times 10^{-1} \mathrm{~g} / \mathrm{L}$
(2) $1 \times 10^{-1} \mathrm{~g} / \mathrm{L}$
(3) $5 \times 10^{-2} \mathrm{~g} / \mathrm{L}$
(4) $2 \times 10^{-2} \mathrm{~g} / \mathrm{L}$
(5) $1 \times 10^{-2} \mathrm{~g} / \mathrm{L}$
(6) $5 \times 10^{-3} \mathrm{~g} / \mathrm{L}$

(a)

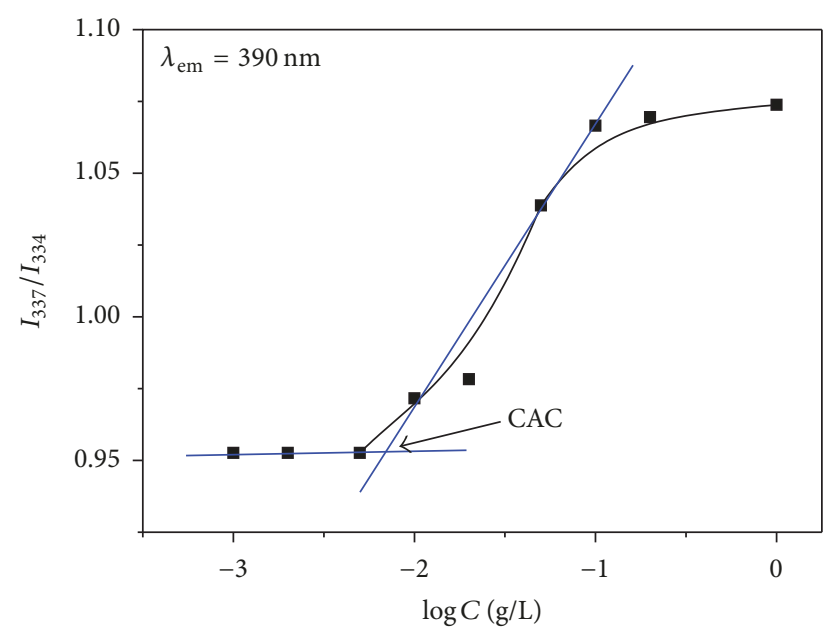

(b)

FIgURE 2: (a) Excitation spectra of pyrene as a function of concentration dependence of PA nanoparticles and (b) plot of $I_{337} / I_{334}$ versus logarithm of the concentration of PA nanoparticles.

intersection of two straight lines. The CAC value is $21.6 \mathrm{mg} / \mathrm{L}$ for PA nanoparticles.

Figures 3(a) and 3(b) show TEM images of synthesized UDCA-PA nanoparticles dispersed on a carbon coated copper grid and negatively stained with $1 \%(\mathrm{w} / \mathrm{v})$ uranyl acetate solution. Most of the UDCA-loaded PA nanoparticles were of spherical shape with a mean diameter of $98 \mathrm{~nm}$ (Figure 3(c)). Figure 3(d) shows zeta potential analysis of UDCA-PA nanospheres. The zeta potential of UDCA-PA nanospheres is negative with a value of $28 \mathrm{mV}$ at $\mathrm{pH}=7.4$.

The UDCA loading efficiency of the PA nanoparticles was found to be around $93 \%$. In order to investigate the stability of FITC-UDCA-loaded PA nanoparticles from the aqueous media, the release profile of FITC-UDCA from nanoparticles was measured in PBS. Results from Figure 4 showed that the release of FITC-UDCA from nanoparticles increased with time with $75 \%$ of FITC-UDCA released in $5 \mathrm{~h}$, while only $35 \%$ of the drug was released in initial $2 \mathrm{~h}$.

3.2. Protective Effects of the UDCA-PA Nanospheres against Glutamate-Induced Excitotoxicity in PC-12 Cells. PC-12 cells were used to compare the neuroprotective effect of UDCA compound alone and encapsulated UDCA in PA (UDCA-PA) nanospheres. The cytotoxicity of PC-12 cells was measured by varying the glutamate concentration in the range of 2-10 mM. Glutamate treatment induces a significant decrease of cell viability in PC-12 cells with dose-dependent tendency. The MTT assay showed that $6 \mathrm{mM}$ glutamate (Figure 5(a)) was the $\mathrm{IC}_{50}$. Therefore, consequent experiments were performed using $6 \mathrm{mM}$ glutamate. Cell viability of PC-12 cells was estimated after treating with UDCA $(1-200 \mu \mathrm{g} / \mathrm{mL})$ alone and UDCA-loaded PA nanospheres $(1-50 \mu \mathrm{g} / \mathrm{mL})$ alone (Figures 5(b) and 5(c)). The MTT assay results are shown in Figure 5(d), glutamate-induced cytotoxicity significantly attenuated by UDCA-PA nanospheres pretreatment dosedependently. Moreover, the result implies that no cytotoxicity was added in the material itself or in the process after encapsulating UDCA in pullulan acetate.

3.3. Antiapoptosis Effect of the UDCA-PA Nanospheres against Glutamate-Induced Apoptosis in PC-12 Cells. To quantitatively demonstrate the antiapoptosis effect of the UDCA-PA nanospheres against glutamate-induced apoptosis, Annexin $\mathrm{V}$ binding assay was performed by MuseTM cell analyzer. Figure 6 shows the apoptosis of control group, glutamate only treated group, and PC-12 cells treated with various concentrations of UDCA-PA nanospheres $(1,5,10,25$, and $50 \mu \mathrm{g} / \mathrm{mL}$ ) with or without glutamate (Figure 6(a)). The neuroprotective mechanism of the UDCA-PA nanospheres was shown to be involved in the mitochondrial-mediated apoptotic pathway; the expressions of apoptosis-related proteins such as caspase- 3 were analyzed by western blot (Figure 6(b)). From the results, caspase- 3 was significantly activated in PC-12 cells treated with $6 \mathrm{mM}$ of glutamate compared to control group. The cleaved caspase-3 protein in UDCA-PA nanospheres $(1 \mu \mathrm{g} / \mathrm{mL}$ and $5 \mu \mathrm{g} / \mathrm{mL})$ treated alone was significantly decreased compared to the control group. These results suggested that UDCA-PA nanospheres inhibited glutamateinduced apoptosis by downregulating cleaved caspase- 3 protein. The effect of UDCA-PA nanospheres on glutamateinduced cell death characteristics, such as nuclease morphology changes, expression, and translocation of caspase- 3 in PC12 cells, was investigated using a confocal microscopy (Figure 7). PC-12 cells normally grow as clumped colonies in plastic flasks and adhesion and disperse as a monolayer over time. From the results, caspase-3 expression was significantly increased in cells treated with $6 \mathrm{mM}$ glutamate more than in the control group. After cells were cotreated with 1 and 


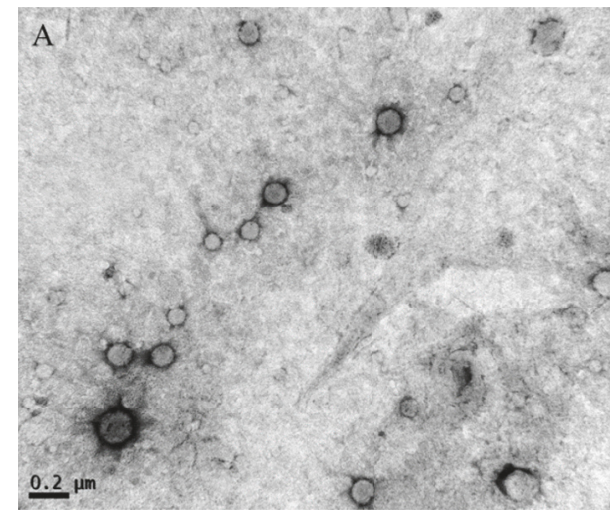

(a)

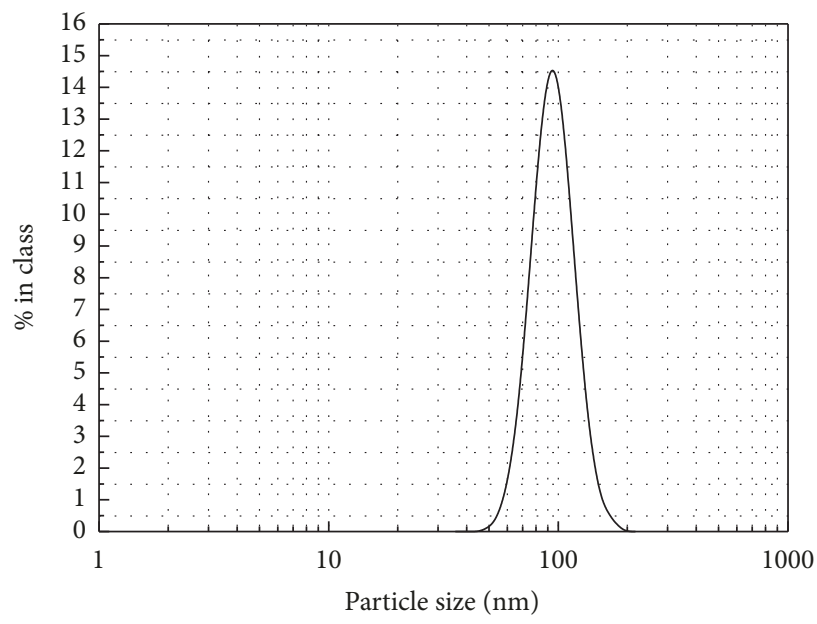

(c)



(b)

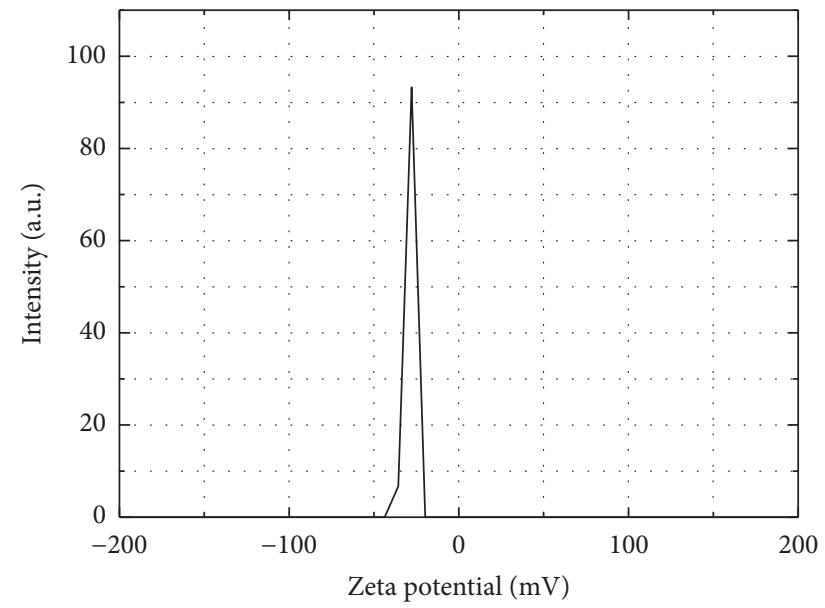

(d)

Figure 3: (a, b) TEM images of synthesized UDCA-loaded PA nanoparticles. The sample was negatively stained with $1 \%$ (w/v) uranyl acetate solution. (c) Particle size distribution and (d) zeta potential analysis of UDCA-PA nanospheres.

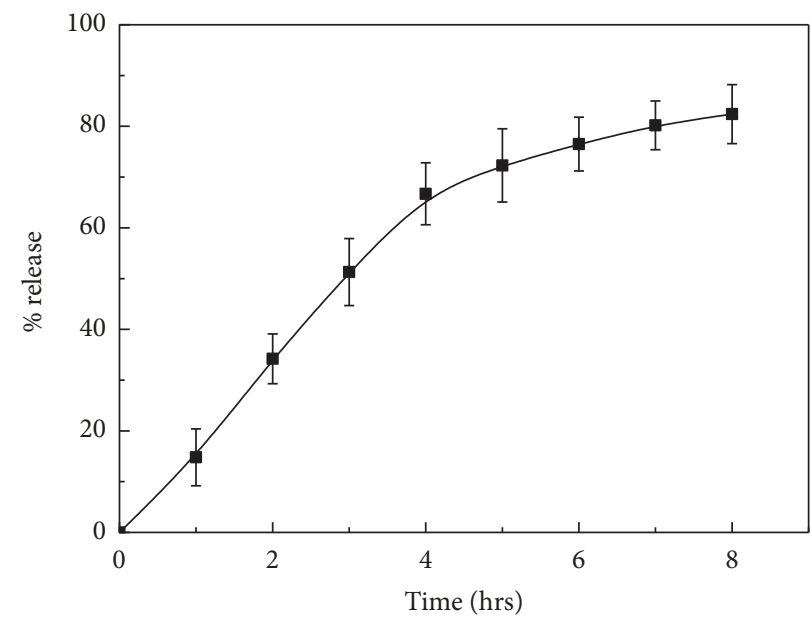

FIgURE 4: Release profile of FITC-UDCA from pullulan acetate nanoparticles in PBS (pH-7.4) at $37^{\circ} \mathrm{C}$. Free FITC-UDCA released from the nanoparticles was filtered through a Millipore filter and its concentration was determined spectrophotometrically. 


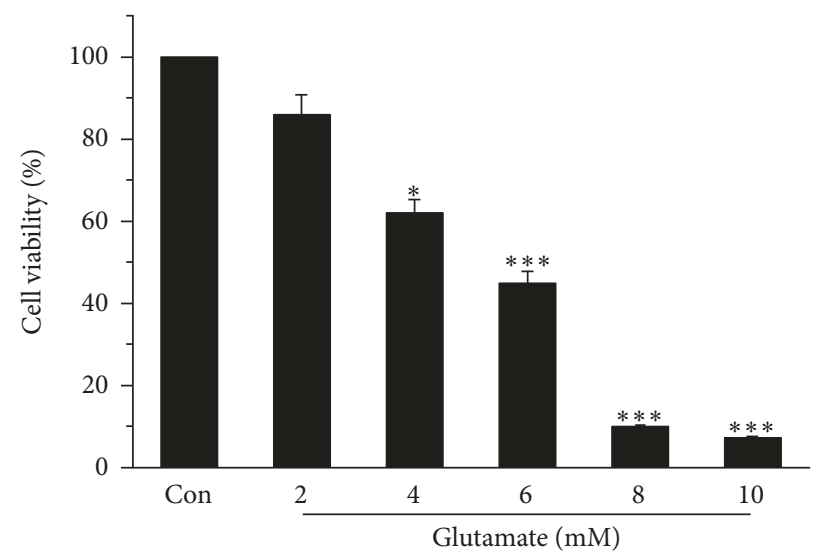

(a)

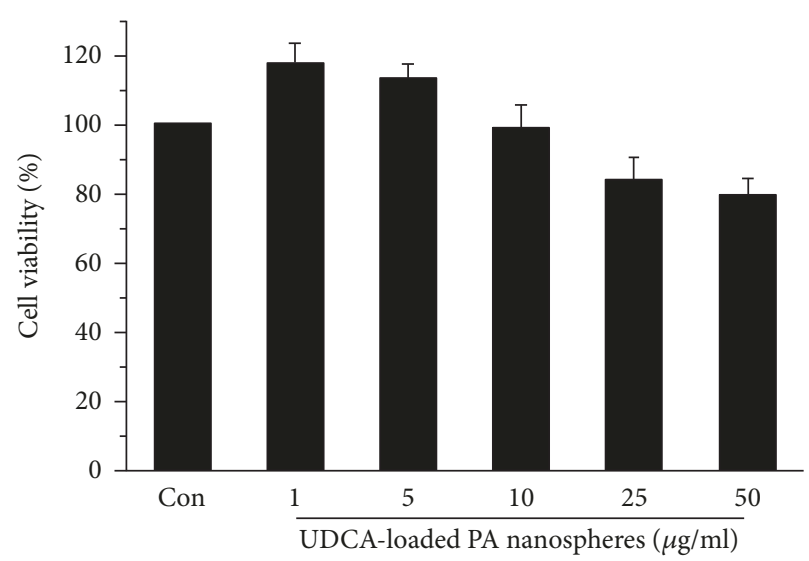

(c)

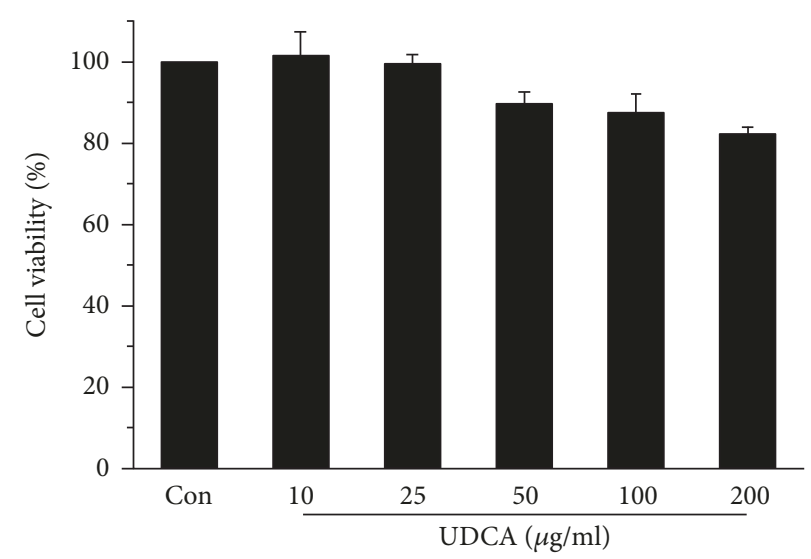

(b)

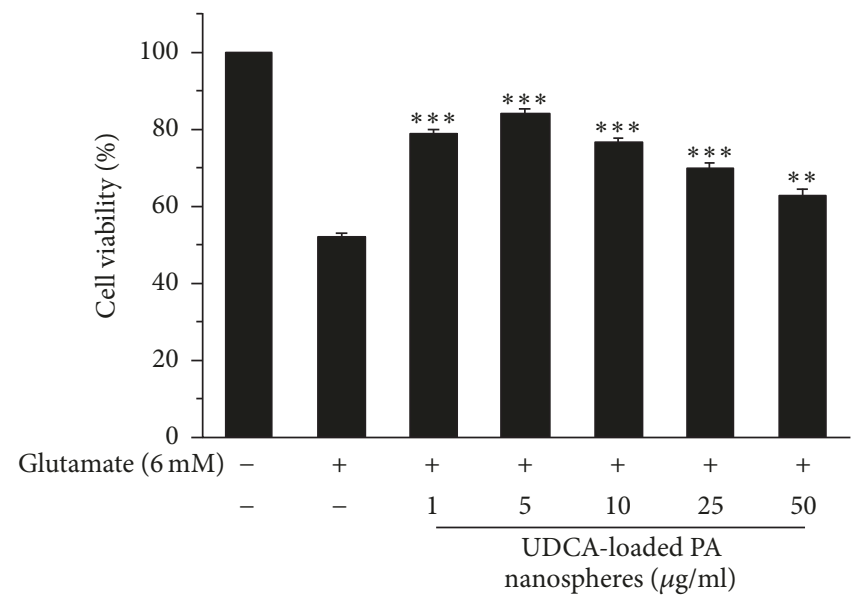

(d)

FIgURE 5: Evaluation of (a) the toxic concentration of glutamate, (b) the safety concentrations of UDCA, (c) the UDCA-PA nanospheres, and (d) the neuroprotective effects of the UDCA-PA nanospheres on the glutamate-induced cell death in PC-12 cells. The cell viability of glutamate $(2-10 \mathrm{mM})$ after exposure to PC-12 cells for $24 \mathrm{~h}\left({ }^{*} p<0.05\right.$ and ${ }^{* * *} p<0.001$ versus Con) and UDCA (1-250 $\left.\mu \mathrm{g} / \mathrm{mL}\right)$ and the UDCA-PA nanospheres $(1-50 \mu \mathrm{g} / \mathrm{mL})$ after exposure to PC-12 cells for $24 \mathrm{~h}$ were evaluated. The neuroprotective effects of the UDCA-PA nanospheres $(1-50 \mu \mathrm{g} / \mathrm{mL})$ against glutamate- $(5 \mathrm{mM})$ induced cell death in PC-12 cells for $24 \mathrm{~h}$ were evaluated $\left({ }^{*} p<0.05,{ }^{* *} p<0.01\right.$, and ${ }^{* * *} p<0.001$ versus glutamate-treated). Data represent the mean \pm SEM from three independent experiments in triplicate. All data are presented as mean \pm SE of the means (SEMs). The statistical analysis was performed using Student's $t$-test (IBM Corporation, Armonk, NY, USA). Results with values less than 0.05 were considered statistically significant.

$5 \mu \mathrm{g} / \mathrm{mL}$ UDCA-PA nanospheres and exposure to glutamate for $24 \mathrm{~h}$, the caspase- 3 expression was increased in them more than in the control group. In addition, in the UDCA-PA nanospheres ( 1 and $5 \mu \mathrm{g} / \mathrm{mL}$ ) only treated PC-12 cells, the caspase- 3 expression was significantly decreased in a dosedependent manner.

The amphiphilic PA is composed of two different moieties, that is, hydrophilic compartment of pullulan and hydrophobic part of acetate. Thus, those amphiphilic behaviors of PA in water are investigated. Pyrene is used as an effective fluorescent probe because it has numerous advantageous physicochemical properties such as long life time and efficient formation of excimers. Fluorescence intensity is maintained at a definite concentration but higher than this concentration increases as a function of the logarithm of the amphipathic polymer concentration. At this critical boundary concentration, is called CAC, micelles are produced in an aqueous medium and pyrene forms an aqueous phase in the aqueous phase and a less polar micelle region. Aside from particle diameter, their inherent surface characteristics, such as surface charge, functional groups, and hydrophobicity, determine the degree of opsonization, which eventually influences the biodistribution of the UDCA-PA nanospheres. Hydrated PVA layers on the surface of the UDCA-PA nanospheres created steric hindrance, which resulted in a highly stable colloidal suspension. Apart from the particle diameter of the UDCA-PA nanospheres, their intrinsic surface characteristics, such as surface charge, functional groups, and hydrophobicity, also determine the quantity of opsonization, influencing the biodistribution of the UDCAPA nanospheres. Generally, UDCA is known as nontoxic compound and cytotoxicity tests exhibited no meaningful 

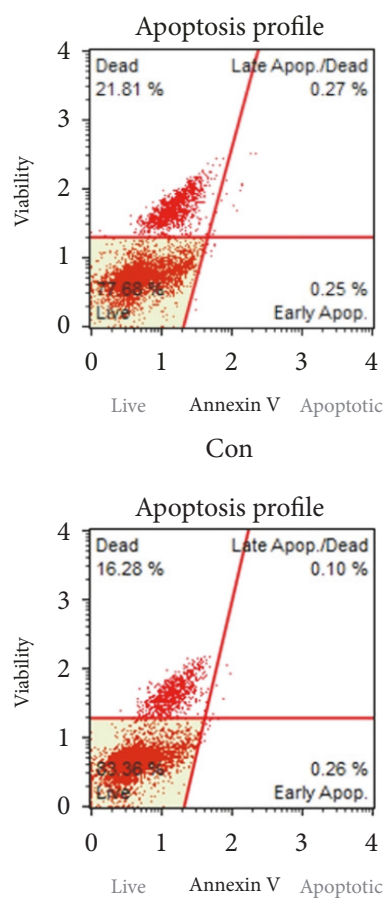

$\mathrm{Glu}+\mathrm{UPN} 10 \mu \mathrm{g} / \mathrm{mL}$


$\mathrm{Glu}+\mathrm{UPN} 25 \mu \mathrm{g} / \mathrm{mL}$

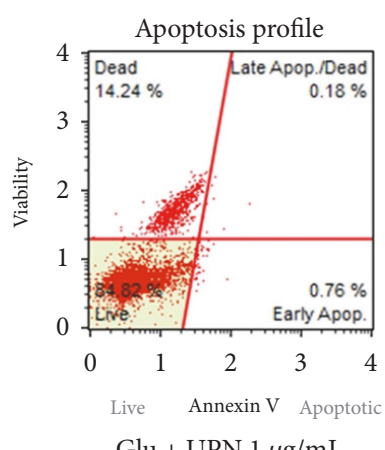

$\mathrm{Glu}+\mathrm{UPN} 1 \mu \mathrm{g} / \mathrm{mL}$

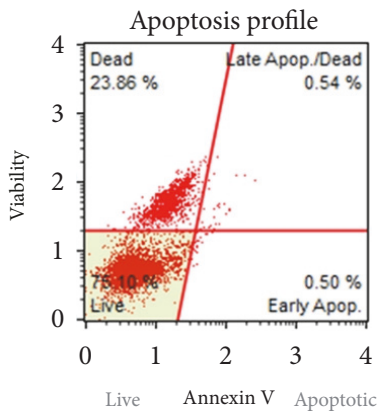

Glu + UPN $50 \mu \mathrm{g} / \mathrm{mL}$

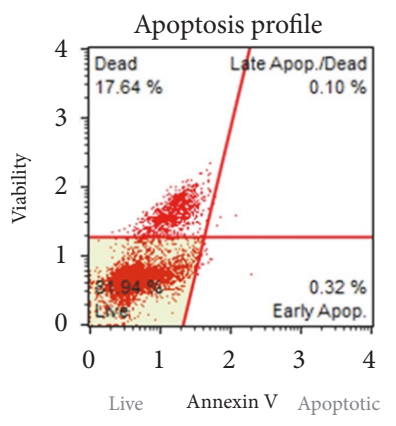

$\mathrm{Glu}+\mathrm{UPN} 5 \mu \mathrm{g} / \mathrm{mL}$



Concentration $(\mu \mathrm{g} / \mathrm{mL})$

吕 Live

$\square$ Early apoptotic

$\otimes$ Late apop/dead

$\square$ Debris

• Total apoptotic

(a)

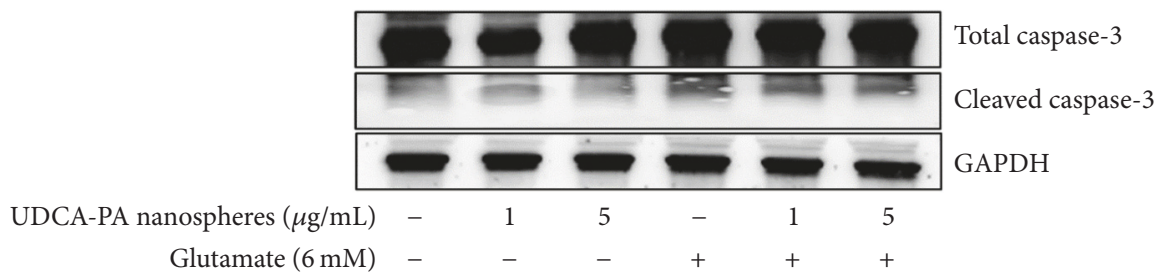

(b)

FIGURE 6: (a) Neuroprotective effects of the UDCA-PA nanospheres $(1-50 \mu \mathrm{g} / \mathrm{mL})$ against glutamate-induced cell death in PC-12 cells were evaluated. Treatment with various concentrations of the UDCA-PA nanospheres for $24 \mathrm{~h}$ in PC-12 cells shows live, early apoptotic, late apoptotic, debris, and total apoptotic cells depending on concentration of the UDCA-PA nanospheres. Abbreviations used: Con, untreated control; UPN, UDCA-PA nanospheres. (b) Western blot assay was performed to analyze the expressions of target proteins, and GAPDH was used as an internal reference. Expressions of cleaved caspase- 3 and caspase- 3 of the UDCA-PA nanospheres $(1$ and $5 \mu \mathrm{g} / \mathrm{mL})$ against glutamate-induced cell death in PC-12 cells were evaluated. Data represent the mean \pm SEM from three independent experiments in triplicate.

difference in cell viability between 10 and $200 \mathrm{ug} / \mathrm{ml}$. These results suggest that the UDCA-PA nanospheres less than $50 \mu \mathrm{g} / \mathrm{mL}$ had no cytotoxicity on PC-12 cells. When treated with $6 \mathrm{mM}$ glutamate, the cell viability was about $50 \%$ against control group. It is known that $80 \%$ of the cell deaths by apoptosis are caused by glutamate-induced cerebral ischemia. As a result, pretreatment with UDCA-PA nanospheres significantly inhibited that apoptosis, which accounts for most of the cell death, resulting in approximately $30 \%$ increase of viability in comparison to the cells treated with glutamate alone. Therefore, additional experiments were conducted to determine the effect of UDCA-PA against glutamate-induced cytotoxicity. When PC-12 cells were treated with 1 50 ug/mL
UDCA-PA nanospheres, there was no specific change in cell viability and those results are similar to MTT assay. PC-12 cells treated with UDCA-PA nanospheres without glutamate implies that apoptosis was not induced. PC-12 cells treated with $6 \mathrm{mM}$ glutamate have increased apoptosis rate compared to the control group, and apoptosis rate was decreased when 1 50 ug/mL UDCA-PA was administered compared to glutamate-treated group. This result implies that administration of UDCA-PA nanospheres at least reduces the rate of apoptosis in ischemia at the cellular level. This is similar to the effect of UDCA shown in other studies, indicating that UDCA-PA is effective in ischemia and that the new DDS does not alter the efficacy. The activation of 


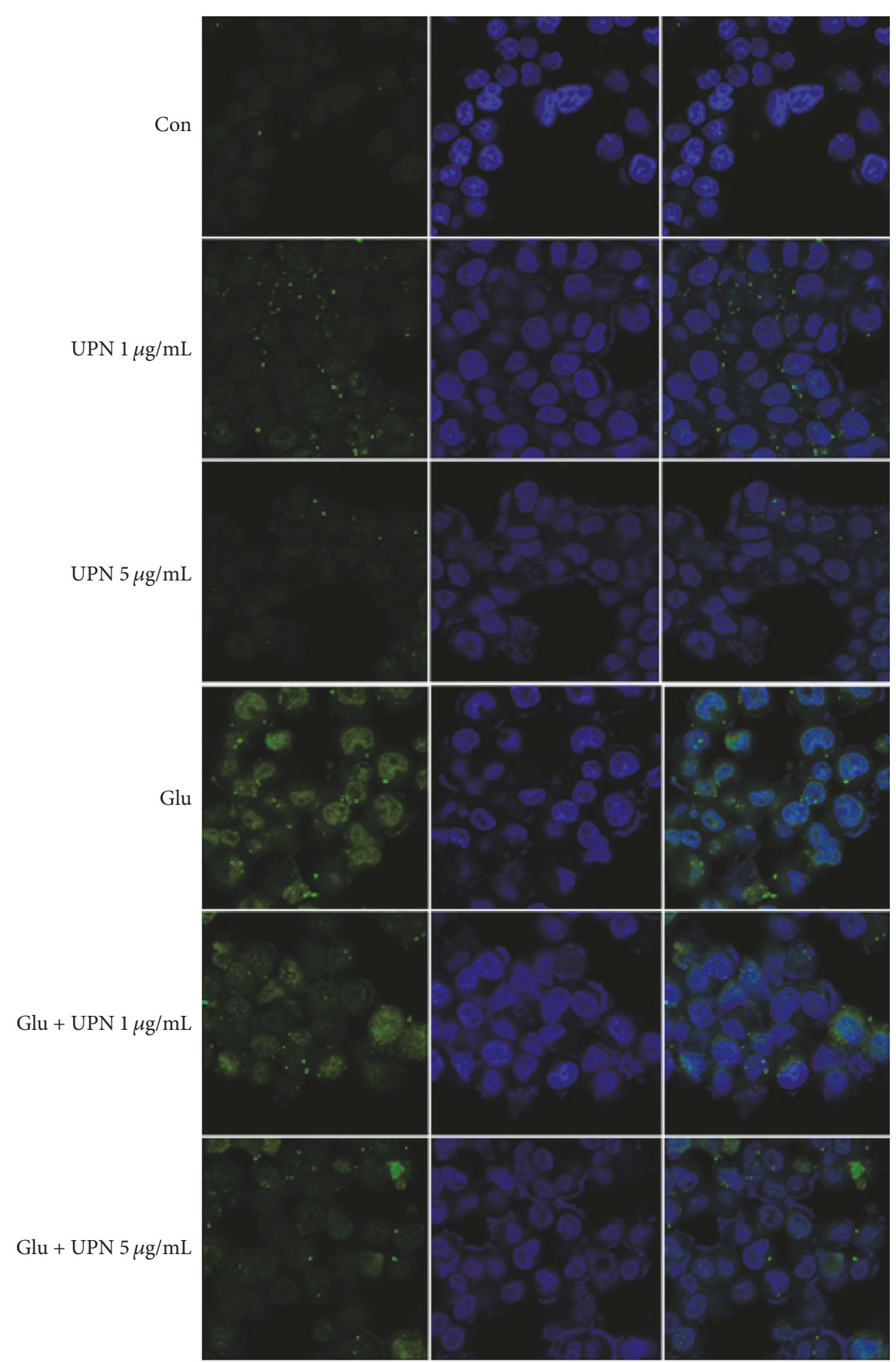

FIGURE 7: Standard images were captured with fluorescence microscope. Changes of caspase-3 expression in PC-12 cells challenged with or without glutamate and subsequently incubated with or without UPN ( 1 or $5 \mu \mathrm{g} / \mathrm{mL})$ were evaluated by immunofluorescence study using anti-caspase-3 antibody (green). DAPI was used for nuclear staining (blue). Abbreviations used: Con, untreated control; UPN, UDCA-PA nanospheres.

caspase cascade is a critical step in the apoptotic cell death pathways.

\section{Conclusions}

The glutamate-induced cytotoxicity significantly was attenuated by UDCA-PA nanospheres pretreatment dose-dependent-ly. Moreover, the result implies that no cytotoxicity was added in the material itself or in the process after encapsulating UDCA in pullulan acetate. When PC-12 cells were treated with 1 50 ug/mL UDCA-PA nanospheres, there was no specific change in cell viability and those results are similar to MTT assay. The neuroprotective mechanism of the UDCA-PA nanospheres was shown to be involved in the mitochondrial-mediated apoptotic pathway, and the expressions of apoptosis-related proteins such as caspase- 3 were analyzed. Based on the results, caspase- 3 was significantly activated in PC-12 cells treated with $6 \mathrm{mM}$ of glutamate 
compared to control group. Therefore, this study suggested that the UDCA-PA nanospheres have potential therapeutic effect on experimental animal model of cerebral ischemia.

\section{Conflicts of Interest}

The authors declare that they have no known conflicts of interest associated with this publication and there has been no competing financial interest for this work that could have influenced its outcome.

\section{Acknowledgments}

This research is financially supported by Basic Science Research Program through the National Research Foundation of Korea (NRF) funded by the Ministry of Education, Science and Technology (Grant no. NRF-2017R1A2B4005167) and Konyang University Myunggok Research Fund.

\section{References}

[1] M. E. Gershwin, C. Selmi, and H. J. Worman, "Risk factors and comorbidities in primary biliary cirrhosis: a controlled interview-based study of 1032 patients," Hepatology, vol. 42, no. 5, pp. 1194-1202, 2005.

[2] U. Beuers, M. H. Nathanson, C. M. Isales, and J. L. Boyer, "Tauroursodeoxycholic acid stimulates hepatocellular exocytosis and mobilizes extracellular $\mathrm{Ca}++$ mechanisms defective in cholestasis," The Journal of Clinical Investigation, vol. 92, no. 6, pp. 2984-2993, 1993.

[3] U. Beuers, D. C. Throckmorton, M. S. Anderson et al., “Tauroursodeoxycholic acid activates protein kinase $\mathrm{C}$ in isolated rat hepatocytes," Gastroenterology, vol. 110, no. 5, pp. 1553-1563, 1996.

[4] L. Qiao, A. Yacoub, E. Studer et al., "Inhibition of the MAPK and PI3K pathways enhances UDCA-induced apoptosis in primary rodent hepatocytes," Hepatology, vol. 35, no. 4, pp. 779-789, 2002.

[5] R. Fiorotto, C. Spirlì, L. Fabris, M. Cadamuro, L. Okolicsanyi, and M. Strazzabosco, "Ursodeoxycholic acid stimulates cholangiocyte fluid secretion in mice via CFTR-dependent ATP secretion," Gastroenterology, vol. 133, no. 5, pp. 1603-1613, 2007.

[6] U. Beuers, M. Bilzer, A. Chittattu et al., "Tauroursodeoxycholic acid inserts the apical conjugate export pump, Mrp2, into canalicular membranes and stimulates organic anion secretion by protein kinase $\mathrm{C}$-dependent mechanisms in cholestatic rat liver," Hepatology, vol. 33, no. 5, pp. 1206-1216, 2001.

[7] U. Leuschner, H. Fischer, W. Kurtz et al., "Ursodeoxycholic acid in primary biliary cirrhosis: results of a controlled double-blind trial," Gastroenterology, vol. 97, no. 5, pp. 1268-1274, 1989.

[8] U. Beuers, J. L. Boyer, and G. Paumgartner, "Ursodeoxycholic acid in cholestasis: potential mechanisms of action and therapeutic applications," Hepatology, vol. 28, no. 6, pp. 1449-1453, 1998.

[9] C. Corpechot, F. Carrat, A.-M. Bonnand, R. E. Poupon, and R. Poupon, "The effect of ursodeoxycholic acid therapy on liver fibrosis progression in primary biliary cirrhosis," Hepatology, vol. 32, no. 6, pp. 1196-1199, 2000.

[10] U. Beuers, "Drug insight: mechanisms and sites of action of ursodeoxycholic acid in cholestasis," Nature Clinical Practice Gastroenterology \& Hepatology, vol. 3, no. 6, pp. 318-328, 2006.
[11] D. W. Choi, "Glutamate neurotoxicity and diseases of the nervous system," Neuron, vol. 1, no. 8, pp. 623-634, 1988.

[12] U. Dirnagl, C. Iadecola, and M. A. Moskowitz, "Pathobiology of ischaemic stroke: an integrated view," Trends in Neurosciences, vol. 22, no. 9, pp. 391-397, 1999.

[13] H. Osuga, S. Osuga, F. Wang et al., "Cyclin-dependent kinases as a therapeutic target for stroke," Proceedings of the National Acadamy of Sciences of the United States of America, vol. 97, no. 18, pp. 10254-10259, 2000.

[14] C. M. P. Rodrigues, G. Fan, X. Ma, B. T. Kren, and C. J. Steer, "A novel role for ursodeoxycholic acid in inhibiting apoptosis by modulating mitochondrial membrane perturbation," The Journal of Clinical Investigation, vol. 101, no. 12, pp. 2790-2799, 1998.

[15] C. M. P. Rodrigues, X. Ma, C. Linehan-Stieers, G. Fan, B. T. Kren, and C. J. Steer, "Ursodeoxycholic acid prevents cytochrome $\mathrm{c}$ release in apoptosis by inhibiting mitochondrial membrane depolarization and channel formation," Cell Death \& Differentiation, vol. 6, no. 9, pp. 842-854, 1999.

[16] S. Arisawa, K. Ishida, N. Kameyama et al., "Ursodeoxycholic acid induces glutathione synthesis through activation of PI3K/Akt pathway in HepG2 cells," Biochemical Pharmacology, vol. 77, no. 5, pp. 858-866, 2009.

[17] C. M. P. Rodrigues, G. Fan, P. Y. Wong, B. T. Kren, and C. J. Steer, "Ursodeoxycholic acid may inhibit deoxycholic acid-induced apoptosis by modulating mitochondrial transmembrane potential and reactive oxygen species production," Molecular Medicine, vol. 4, no. 3, pp. 165-178, 1998.

[18] C. M. P. Rodrigues, C. L. Stieers, C. D. Keene, and X. $\mathrm{Ma}$, "Tauroursodeoxycholic acid partially prevents apoptosis induced by 3-nitropropionic acid: evidence for a mitochondrial pathway independent of the permeability transition," Journal of Neurochemistry, vol. 75, no. 6, pp. 2368-2379, 2000.

[19] Y. Zhang, H. F. Chan, and K. W. Leong, "Advanced materials and processing for drug delivery: the past and the future," Advanced Drug Delivery Reviews, vol. 65, no. 1, pp. 104-120, 2013.

[20] P. Y. Teo, W. Cheng, J. L. Hedrick, and Y. Y. Yang, "Co-delivery of drugs and plasmid DNA for cancer therapy," Advanced Drug Delivery Reviews, vol. 98, pp. 41-63, 2016.

[21] R. M. Koffie, C. T. Farrar, L.-J. Saidi, C. M. William, B. T. Hyman, and T. L. Spires-Jones, "Nanoparticles enhance brain delivery of blood-brain barrier-impermeable probes for in vivo optical and magnetic resonance imaging," Proceedings of the National Acadamy of Sciences of the United States of America, vol. 108, no. 46, pp. 18837-18842, 2011.

[22] Z. Liu, Y. Shen, Y. Wu et al., "An intrinsic therapy of gold nanoparticles in focal cerebral ischemia-reperfusion injury in rats," Journal of Biomedical Nanotechnology, vol. 9, no. 6, pp. 1017-1028, 2013.

[23] S. L. Friedman, "Liver fibrosis-from bench to bedside," Journal of Hepatology, vol. 38, pp. S38-S53, 2003.

[24] R. Bataller and D. A. Brenner, "Liver fibrosis," The Journal of Clinical Investigation, vol. 115, no. 2, pp. 209-218, 2005.

[25] K. S. Soppimath, T. M. Aminabhavi, A. R. Kulkarni, and W. E. Rudzinski, "Biodegradable polymeric nanoparticles as drug delivery devices," Journal of Controlled Release, vol. 70, no. 1-2, pp. 1-20, 2001.

[26] M. Beija, R. Salvayre, N. Lauth-de Viguerie, and J. Marty, "Colloidal systems for drug delivery: from design to therapy," Trends in Biotechnology, vol. 30, no. 9, pp. 485-496, 2012. 
[27] Y. Motozato, H. Ihara, T. Tomoda, and C. Hirayama, "Preparation and gel permeation chromatographic properties of pullulan spheres," Journal of Chromatography A, vol. 355, no. C, pp. 434437, 1986.

[28] P. R. Ravi, R. Vats, J. Balija, S. P. N. Adapa, and N. Aditya, "Modified pullulan nanoparticles for oral delivery of lopinavir: formulation and pharmacokinetic evaluation," Carbohydrate Polymers, vol. 110, pp. 320-328, 2014.

[29] Y. Byun, J. B. Hwang, S. H. Bang et al., "Formulation and characterization of $\alpha$-tocopherol loaded poly $\varepsilon$-caprolactone (PCL) nanoparticles," LWT- Food Science and Technology, vol. 44, no. 1, pp. 24-28, 2011. 


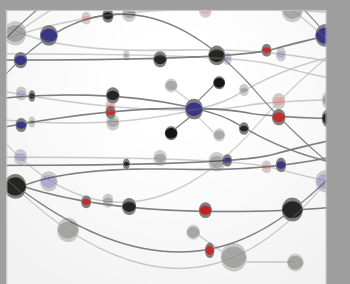

The Scientific World Journal


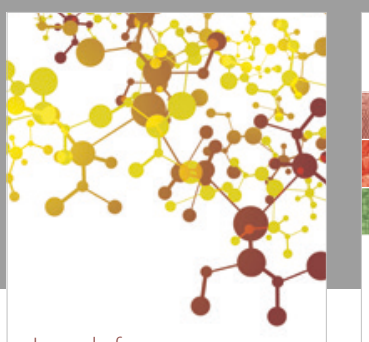

Journal of

Applied Chemistry
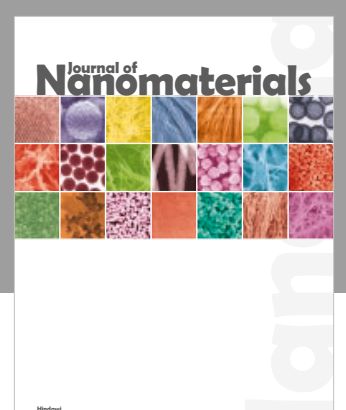



Scientifica

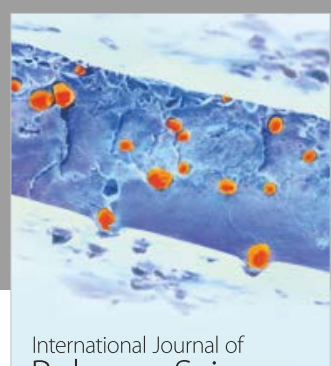

Polymer Science

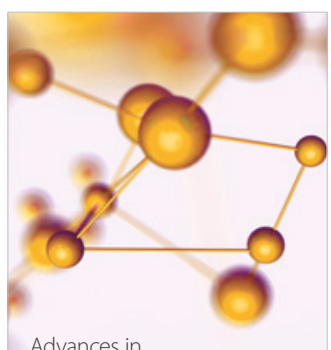

Physical Chemistry
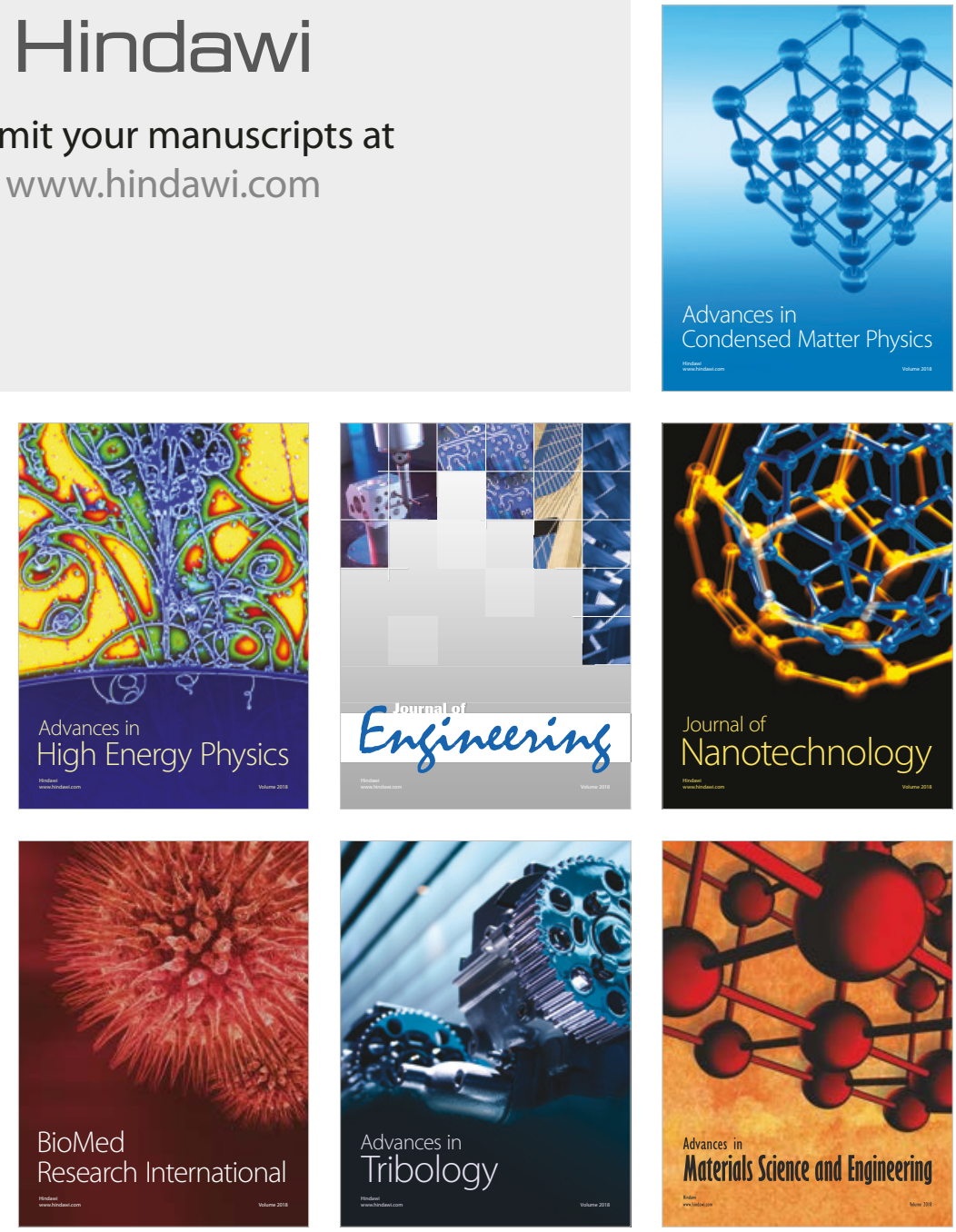